\title{
Cadeia produtiva de produtos florestais não madeireiros: o caso da mangabeira (Hancornia speciosa Gomes) em Sergipe, Brasil
}

\section{Productive chain of non-wood forest products: the mangabeira (Hancornia speciosa Gomes) case in Sergipe, Brazil}

\author{
Débora Moreira de Oliveira $^{1 *}$, Thiago Roberto Soares Vieira ${ }^{2}$, Laura Jane Gomes ${ }^{2}$
}

\begin{abstract}
RESUMO
O estudo das cadeias produtivas (CP) de Produtos Florestais Não Madeireiros é essencial para compreender a sustentabilidade na exploração destes recursos. O objetivo da pesquisa foi caracterizar a estrutura geral da CP do fruto da mangabeira (Hancornia speciosa Gomes) no estado de Sergipe. Para coleta de dados foram realizadas revisões bibliográficas, oficinas e entrevistas com os diferentes atores sociais envolvidos na $\mathrm{CP}$, identificados mediante amostragem intencional não probabilística. Foi constatado que a estrutura da $\mathrm{CP}$ da mangaba no estado de Sergipe possui a configuração de um "Complexo Agroextrativista da Mangaba", articulado em três eixos que se interconectam: extrativismo tradicional, extrativismo associativista e produção comercial (plantio). Neste sentido, configura-se como uma CP dinâmica, com particularidades complexas que precisam ser melhor compreendidas a fim de evitar os entraves à sustentabilidade da exploração do fruto.
\end{abstract}

Palavras-chave: sociobiodiversidade; fluxo de comercialização; sustentabilidade.

\begin{abstract}
The study of non-timber forest products production chains (CP) is essential to understand sustainability in the exploitation of these resources. The objective of this research was to characterize the general structure of CP of mangaba fruit (Hancornia speciosa Gomes) in Sergipe state. For data collection, bibliographic reviews, workshops and interviews were conducted with the different social actors involved in PC, identified through intentional non-probabilistic sampling. It was found that the mangaba $\mathrm{CP}$ structure in the state of Sergipe has the configuration of a "Mangaba Agro-extractivist Complex", articulated in three interconnected axes: traditional extractivism, associative extractivism and commercial production (planting). In this sense, it is configured as a dynamic PC, with complex particularities that need to be better understood in order to avoid obstacles to the sustainability of mangaba fruit exploitation.
\end{abstract}

Keywords: socio-biodiversity; marketing flow; sustainability.

\footnotetext{
${ }^{1}$ Universidade Federal de Sergipe. *E-mail: d.oliveira.doc@ gmail.com

2 Universidade Federal de Sergipe.
} 


\section{INTRODUÇÃO}

O conceito de "cadeia produtiva" tem progredido na direção de uma melhor formatação, do ponto de vista teórico, devido às várias correntes de pensamento econômico. Apesar da multiplicidade de termos adotados por economistas e estudiosos dos complexos agroindustriais (BATALHA, SILVA, 2007; ARAÚJO, 2009), nos últimos anos, o termo "cadeia produtiva" foi o que se popularizou em diversos trabalhos (GOMES, 1998; ENRIQUEZ, 2008; JESUS, 2010; MOTA et al. 2011a) onde o produto principal da cadeia é um Produto Florestal Não Madeireiro (PFNM), que, não necessariamente, se encaixa nos modelos tradicionais de "cadeia produtiva".

Assim, reconhecendo o conceito de cadeia produtiva e sua aplicação no caso do extrativismo de PFNM, foi instituído o Plano Nacional para a Promoção dos Produtos da Sociobiodiversidade (PNPSB) (BRASIL, 2009). O documento descritivo do plano traz inclusive a definição do conceito de cadeia produtiva adotado e, também, um novo conceito: o de "cadeia produtiva da sociobiodiversidade".

O fato é que, apesar de o termo "cadeia produtiva" ser aceito nas rodas acadêmicas e nas políticas públicas relacionadas ao extrativismo de PFNM, é certo que, nem sempre, a cadeia produtiva de um PFNM vai se encaixar nos moldes de uma cadeia produtiva agroindustrial típica, o que leva à inclusão de novos conceitos. Assim, o autor Enríquez (2008), analisando cadeias produtivas de PFNM da Amazônia, afirma que estas se enquadram em uma "cadeia produtiva da biodiversidade", oposta ao modelo "tradicional" de cadeia produtiva.

Nesse contexto, há o extrativismo da mangaba no Brasil, que é relatado em escritos desde a época da colonização do país (SILVA JÚNIOR; MOTA; SCHMITZ, 2011). O estado de Sergipe se destaca sob a ótica dos conhecimentos, usos e aproveitamentos da mangaba pelas populações locais. Neste estado, desde a década de 60 boletins técnicos nomearam a espécie como "Rainha dos Tabuleiros" (SILVA JÚNIOR et al., 2011).

Devido à pressão imobiliária nas capitais nordestinas e cidades turísticas houve uma diminuição da produção regional de mangaba. Em comparação aos demais estados do nordeste, a queda da produção foi mais lenta em Sergipe, contudo, a partir da década de 90 a paisagem litorânea tem sido rapidamente transformada, aumentando a vulnerabilidade da espécie (SILVA JÚNIOR; MOTA; SCHMITZ, 2011). 
Nos dados divulgados nos últimos 10 anos pelo Panorama do Extrativismo Vegetal e da Silvicultura (PEVS), Sergipe ocupou nove vezes a primeira posição como maior produtor de mangaba do Brasil, contudo, nota-se ano a ano uma queda na produção - em 2007 foram 436 toneladas e em 2016 foram 190 toneladas (IBGE 2007; IBGE, 2016). Pode explicar esta queda a redução de 29,6\% (10.456 hectares) das áreas naturais remanescentes de ocorrência da mangabeira em Sergipe entre os anos de 2011 e 2016 (RODRIGUES et al., 2017).

Reconhecendo o significado cultural e econômico da espécie para o estado, apesar do acelerado processo de redução que a espécie vem sofrendo, foi promulgado o Decreto Estadual $n^{\circ} 12.723 / 1992$, que instituiu a mangabeira como símbolo do estado de Sergipe (SERGIPE, 1992). Alguns anos depois, foi promulgada a Lei Estadual n ${ }^{\circ} 7.082 / 2010$, que reconheceu as catadoras de mangaba como grupo culturalmente diferenciado e que precisa ser protegido (SERGIPE, 2010).

Apesar do interesse recente na temática das catadoras de mangaba e de pesquisas que enfocam as representações sociais da catadoras de mangaba (MOTA et al., 2011b) e as técnicas para o cultivo comercial da espécie (LÊDO et al. 2015), entende-se que ainda há carência de um detalhamento da cadeia produtiva da mangaba de Sergipe, visto que, conforme a análise da coletânea bibliográfica acadêmica realizada por Oliveira et al. (2017), constatou-se que há uma carência desses estudos no estado.

Dessa forma, surgiram os seguintes questionamentos: Quais são e como se caracterizam as diferentes etapas de transformação e transferência dos produtos oriundos da mangaba e os atores nelas envolvidos, no estado de Sergipe? Assim, este trabalho teve como objetivos: 1) caracterizar a estrutura geral da cadeia produtiva da mangaba no estado de Sergipe e 2) conhecer os diferentes atores sociais e os velhos e novos arranjos envolvidos bem como os canais de comercialização utilizados.

\section{MATERIAL E MÉTODOS}

\section{$\underline{\text { Área de estudo e fases da pesquisa }}$}

A área de estudo foi delimitada com base na ocorrência de extrativismo do fruto da mangabeira nos municípios sergipanos: Aracaju, Barra dos Coqueiros, Estância, Indiaroba, Itaporanga D’Ajuda, Japaratuba, Japoatã, Pacatuba, Pirambu, Santa Luzia do Itanhy, Santo Amaro das Brotas e São Cristóvão (PEREIRA et al., 2009). 
A coleta de dados em campo foi subdividida em três fases, de acordo com o público-alvo selecionado: FASE 1 - oficinas com extrativistas; FASE 2 - entrevistas a feirantes (extrativistas e não extrativistas); FASE 3 - entrevistas a indústrias beneficiadoras, atravessadores, líderes de comunidades extrativistas e proprietários de terras com ocorrência natural e/ou cultivada da espécie.

Na FASE 1 foi realizada uma oficina com uso de ferramentas de Diagnóstico Rápido Participativo (DRP) (VERDEJO, 2006) empregadas a fim de descrever o sistema (cadeia produtiva da mangaba). Para as FASES 2 e 3 foi utilizada a entrevista semiestruturada (MARCONI; LAKATOS, 2008), contendo perguntas relativas à atividade de cada tipo de ator social envolvido na cadeia produtiva da mangaba.

\section{Seleção do público-alvo}

O público-alvo foram os atores sociais relacionados ao extrativismo e comercialização dos frutos da mangabeira in natura e/ou beneficiados, isto é: extrativistas, donos de propriedades com ocorrência natural e/ou cultivada da espécie, atravessadores, indústrias beneficiadoras e feirantes.

A seleção destes deu-se por meio de amostragem não probabilística intencional (MARCONI; LAKATOS, 2008; MAROTTI et al., 2008), pois a ausência de um dado oficial acerca do número de atores sociais envolvidos na cadeia produtiva da mangaba no estado de Sergipe impossibilita o cálculo amostral probabilístico.

No caso dos atores sociais extrativistas, optou-se por contatar comunidades extrativistas que possuem Associações de Catadoras de Mangaba (ACM) e/ou participam do Movimento das Catadoras de Mangaba de Sergipe (MCM). Cinco ACM (de um total de sete no estado de Sergipe) aceitaram participar da pesquisa - três no litoral sul do estado e duas no litoral norte.

Para a seleção de donos de propriedades com ocorrência natural e/ou cultivada da espécie, atravessadores e indústrias beneficiadoras, foi adotado contato direto (visitas à residência ou local de trabalho) e adaptação da metodologia para seleção intencional de informantes conhecida como snowball ou bola-de-neve (ALBUQUERQUE; LUCENA; NETO, 2014) - o que levou à novas buscas e novos informantes, sucessivamente, por meio de indicações.

Para a seleção dos feirantes (extrativistas e não extrativistas) foram visitadas as feiras indicadas durante as oficinas nas ACM (feiras onde se destacam a venda do fruto 
da mangaba), totalizando 16 feiras em 15 municípios. Foi ainda investigado o "caminho inverso" da cadeia produtiva, por meio, por exemplo, da busca e contato em casas de comercialização de Aracaju e por meio de contato direto junto a fabricantes de polpas de fruta e sorvetes de mangaba.

Após a adoção destes procedimentos, participaram 57 extrativistas (destes, 13 são também proprietários de terra), 15 feirantes não-extrativistas, cinco atravessadores, quatro proprietários de terra e cinco proprietários de indústrias. Todos os participantes assinaram o Termo de Consentimento Livre e Esclarecido (TCLE), previamente aprovado por Comitê de Ética e Pesquisa.

Análise de dados e apresentação de resultados

Os dados coletados foram anotados e analisados de maneira quali-quantitativa (LAKATOS, 2008), compilados através da metodologia de triangulação (LAKATOS, 2008; VERDEJO, 2006). Nesta pesquisa foram utilizadas a triangulação de dados (na medida em que foram coletados dados com diferentes grupos de informantes) e a metodológica (empregados mais de um método na coleta de dados) (SILVA; GOMES; ALBUQUERQUE, 2014).

Os resultados foram apresentados de acordo com os pontos de diferenças fundamentais entre uma cadeia produtiva "tradicional" e uma cadeia produtiva "da biodiversidade" estabelecidos por Enriquez (2008) e Gomes (1998), com ajustes necessários às características particulares da cadeia produtiva da mangaba em Sergipe.

\section{RESULTADOS E DISCUSSÃO}

\section{$\underline{\text { Insumos e serviços }}$}

Foi analisada a presença/ausência dos seguintes insumos: água, energia, corretivos de solos, fertilizantes, agroquímicos, compostos orgânicos e materiais genéticos (sementes, mudas). Na cadeia produtiva da mangaba em Sergipe destacam-se os provedores dos insumos básicos, tais como água e energia.

A água é utilizada na limpeza dos frutos e entra na composição de produtos beneficiados (polpa, sorvetes, doces em geral), enquanto a energia é utilizada para o funcionamento de equipamentos diversos (seladoras, dosadoras, câmaras de resfriamento, freezers, esteiras de lavagem, etc) nas Unidades de Beneficiamento do Fruto (UB), sob 
responsabilidade das ACM e Indústrias. A energia também é utilizada nos freezers de atravessadores - dos três atravessadores entrevistados, dois possuem o equipamento para estocar o fruto in natura.

Alguns atores sociais relataram sobre a dificuldade de manter o estoque dos frutos e/ou dos produtos mediante os custos elevados da água e da energia. Os extrativistas que trabalham nas UB relataram que, além disso, têm dificuldades com os gastos para rotulagem dos produtos e aluguel de um ponto de venda fixo.

Também foi mencionada a dificuldade para se deslocar para os locais de venda dos produtos beneficiados. Os feirantes extrativistas relataram pagar entre $R \$ 50$ e $R \$$ 150 para levar os frutos para as feiras, a depender da distância em que levam a mangaba para comercialização. Isso, além de outros aspectos, faz com que os lucros para os extrativistas sejam baixos.

Com base em um relato foi possível notar que determinado extrativista vende em média 100 litros do fruto por mês, angariando $R \$ 400$ reais; contudo, gasta $R \$ 200$ com transporte; e, descontando-se ainda o valor que paga ao dono do sítio para coletar a mangaba, R\$ 40, fica com apenas $\mathrm{R} \$ 160$ de ganho líquido ${ }^{3}-40 \%$ do valor total obtido com a venda dos frutos.

Por sua vez, os proprietários de terra e os atravessadores relataram dificuldades tanto com o gasto com transporte (combustível e frete) quanto com a manutenção dos freezers (gastos com energia) e mão-de-obra. Contudo, não souberam informar o valor gasto com cada insumo e, portanto, não foi possível estimar o quanto estes elementos impactam nos ganhos finais.

Os insumos utilizados diretamente em ações de cultivo pouco foram citados. Os três proprietários de terra que relataram ter realizado o plantio de mudas de mangabeira, afirmaram tê-lo feito em covas, por meio do lançamento do fruto inteiro, sem a adição de nenhum corretivo para o solo. A compra de mudas foi relatada por apenas um deles, que relatou ter adquirido 3.000 mudas de um pesquisador da Empresa de Desenvolvimento Agropecuário de Sergipe - EMDAGRO, no ano de 1999. As plantas estavam com $30 \mathrm{~cm}$ de altura, e foram plantadas em covas sem uso de fertilizante químico, mas com uso de trator agrícola para limpeza do terreno.

\footnotetext{
${ }^{3}$ Como a referida entrevista foi realizada no primeiro sementre de 2016, segue, para fins comparativos, a cotação do DÓLAR DOS EUA no período de 01/01/2016 a 30/06/2016: média simples do período 3,70 (compra e venda), cotação em Real. Disponível em: https://www.bcb.gov.br
} 
Dos 13 extrativistas "com terra" entrevistados, apenas três relataram que já realizaram o plantio da mangabeira, de duas maneiras: produzindo suas próprias mudas (1) ou lançando o fruto diretamente ao solo (2).

Apenas um entrevistado (o que comprou as mudas da EMDAGRO) afirmou que teve orientação para realizar o plantio das mangabeiras. Os demais, afirmaram realizar o plantio com os seus próprios conhecimentos, e com o conhecimento comum local. Os autores Pereira, Pereira e Junqueira (2006) tratam do plantio por sementes, contudo, os autores recomendam a seleção dos frutos e a extração das sementes por maceração dos frutos em peneira, afirmando que, no caso da implantação de pomares, a "propagação por semente requer seleção de plantas-matrizes sadias e vigorosas, com alta produtividade e frutos de boa qualidade".

Mediante o exposto, nota-se que tanto os tipos quanto o volume de insumos são menores em relação aos utilizados em cadeias produtivas tradicionais - que preconizam o uso intensivo de mão-de-obra e maquinários (ENRÍQUEZ, 2008). Como a produção no estado de Sergipe é proveniente quase em sua totalidade de áreas naturais e as áreas plantadas se encontram em terrenos de ocorrência natural da espécie - isto é, na prática, predomina um enriquecimento da área de ocorrência natural - predomina a lógica de exploração de cadeias produtivas da biodiversidade onde o uso de insumos é inexistente ou muito baixo.

Foi ainda analisada a presença/ausência dos seguintes Serviços: pesquisas, fomento, extensão rural e assistência técnica, créditos e financiamentos. Destaca-se neste setor a atuação da Embrapa Tabuleiros Costeiros, com o desenvolvimento de pesquisas relacionadas ao tema, dentre elas, as de Pereira et al. $(2009,2010)$ e Mota et al. (2011a), que estudaram os aspectos socioeconômicos relacionados à espécie, e a de Silva Júnior e Lédo (2006), que organizaram uma coletânea denominada “A cultura da mangaba" - que contou com a contribuição de diversos autores sobre aspectos botânicos, ecofisiológicos, de interação faunística (polinização), recursos genéticos, propagação por sementes, propagação por enxertia, micropropagação, implantação de pomar e práticas culturais, nutrição mineral e adubação, doenças e pragas, colheita e pós-colheita e tecnologia e processamento do fruto da mangabeira.

Além das pesquisas, outro importante componente são os serviços de Fomento, Extensão Rural e Assistência Técnica, bem como os Créditos e Financiamentos (ARAÚJO, 2009). Em nível estadual, as instituições responsáveis pela extensão Rural e 
assistência técnica são a Secretaria de Agricultura do Estado de Sergipe - SEAGRI-SE e a EMDAGRO. É importante destacar que todos os atores sociais entrevistados apontaram um déficit no provimento de serviços de fomento, extensão rural e assistência técnica, bem como créditos e financiamentos.

Em nível federal, os extrativistas podem ter acesso ao "Programa Fomento Rural" que apoia investimentos de famílias rurais que se encontram em situação de pobreza por meio da oferta de serviços de assistência técnica e extensão rural (Ater) - contudo, na presente pesquisa, nenhuma família entrevistada foi contemplada por este programa. Outro importante instrumento para o fortalecimento da agricultura familiar em nível federal é o Programa de Aquisição de Alimentos (PAA) (BRASIL, 2012) - segundo Schmitz, Mota e Souza (2016), o PAA foi importante fonte de recursos para catadoras de mangaba do município de Indiaroba-SE, que, entre 2007 e 2011 por meio do fornecimento de frutos ao referido programa.

É importante destacar que, por se tratar de um PFNM, ações de extensão e fomento deveriam partir de um Instituto Estadual de Florestas, como parte de um Plano Estadual de Fomento Florestal, a exemplo do que realiza o estado de Minas Gerais (IEF-MG, 2012). Porém, tal órgão inexiste no estado de Sergipe, aliás, nem mesmo a Política Estadual de Florestas foi aprovada até o momento - apesar de uma série de estudos ter sido realizada pela então Secretaria de Estado do Meio Ambiente e dos Recursos Hídricos de Sergipe (SEMARH-SE) ${ }^{4}$ e publicada em 2012 (SERGIPE, 2012).

Em consulta a duas entidades bancárias atuantes em Sergipe, foi constatado que não há linha de crédito específica para produtores de mangaba, porém, as linhas de crédito rural disponíveis poderiam ser utilizadas por produtores rurais de mangaba caso tivessem conhecimento sobre essas modalidades de crédito - os entrevistados afirmaram que não há registro de linha de crédito com esse perfil.

Comparativamente, no estado do Espírito Santo, há incentivo específico para o produtor rural que planta a aroeira da praia (Schinus terebinthifolius Raddi), visto que no estado há indústrias processadoras-exportadoras da pimenta rosa (coproduto do fruto da aroeira da praia) que formam um arranjo produtivo integrado que tem linhas de financiamento ao produtor rural fornecidas pelo Banco do Estado do Espírito Santo, bem

\footnotetext{
${ }^{4}$ Em dezembro de 2018 a SEMARH foi extinta e suas funções passaram à Secretaria de Estado do Desenvolvimento Urbano e Sustentabilidade - SEDURBES.
} 
como assistência técnica ao produtor rural e extrativistas através da Empresa Capixaba de Pesquisa Agropecuária (JESUS; GOMES, 2010).

Mediante o exposto, em relação aos serviços ofertados para suprir a cadeia produtiva da mangaba no estado de Sergipe, nota-se que há carência destes, conforme foi apontado por todos os atores sociais envolvidos, e, portanto, no provimento de serviços a cadeia produtiva da mangaba também se aproxima da lógica encontrada em típicas cadeias da biodiversidade.

\section{Escala de produção, preço e características da matéria-prima}

Tanto extrativistas "com-terra" quanto proprietários de terra não souberam afirmar qual a produção total de suas áreas, pois afirmaram não manter registros anuais do quanto coletam. Contudo, souberam estimar a quantidade coletada.

A quantidade de frutos coletada por ano, com média entre o que foi coletado nos anos de 2016 e 2017, estimados pelos três tipos de atores sociais foram: $49.500 \mathrm{~kg}$ de fruto coletado por proprietários de áreas, $6.336 \mathrm{~kg}$ do fruto coletado por extrativistas "com-terra" e $26.100 \mathrm{~kg}$ coletados por extrativistas "sem-terra". Somando estes valores tem-se que foram coletados, em média, $81.936 \mathrm{~kg}$ ou aproximadamente 82 toneladas de mangaba pelos atores sociais entrevistados no ano de 2016 e também no ano de 2017. Assim, a quantidade coletada informada pelos entrevistados equivale a $43,1 \%$ da quantidade total coletada em Sergipe (190 toneladas) no ano de 2016, segundo o Panorama do Extrativismo Vegetal e da Silvicultura (PEVS) (IBGE, 2016).

Por sua vez, informações cedidas por e-mail por uma cooperativa que agrega diversos produtores de mangaba nativa e plantada dos municípios de Japaratuba e Pirambu apontam que no ano de 2005 os 6.274 pés de mangabeira produziram em média $36 \mathrm{~kg} /$ pé, e que, como no ano houve duas safras, isso totalizou uma produção de aproximadamente $451.728 \mathrm{~kg}$ (451,728 toneladas) no ano. Segundo dados do PEVS (IBGE, 2005) no ano de 2005 o estado de Sergipe como um todo produziu 497 toneladas de mangaba, isto é, se levado em consideração a estatística do IBGE para o ano de 2005, apenas a produção da cooperativa equivaleria à $90,1 \%$ de toda a produção estadual no ano.

Os três atravessadores entrevistados não forneceram informações que permitissem estimar a quantidade de frutos adquirida. Por sua vez, somando a média que todos os feirantes não extrativistas afirmaram comprar por mês foi encontrado o valor aproximado 
de 2300 litros por semana, o que daria 9.200 litros por mês, o que, em seis meses de safra corresponderia a 55200 litros de mangaba por ano, ou $27.600 \mathrm{~kg}$, o que equivale a $14,5 \%$ da quantidade total coletada em Sergipe no ano de 2016, segundo o PEVS (IBGE, 2016).

Os proprietários de indútrias mantinham controle sobre a quantidade de frutos adquirida. Somando-se todos os dados disponibilizados, constatou-se que os cinco proprietários de indústria entrevistados adquiriram em media 250 toneladas de mangaba no ano de 2016, proveniente do estado de Sergipe (visto que não foi informada a compra de frutos vindos de outros estados), o que ultrapassa em 60 toneladas a quantidade total coletada em Sergipe no ano de 2016, segundo o PEVS (IBGE, 2016).

Ressalta-se que a comercialização da mangaba é realizada na "beira da pista", em feiras, nos mercados e Companhia de abastecimento de Aracaju - CEASA, em lanchonetes, em minimercados, dentre outros. Assim, mediante análise dos resultados, surge a suspeita de que os dados de coleta de mangaba no estado de Sergipe estão subestimados nos relatórios PEVS.

Foi constatado por meio de consulta à Secretaria da Fazenda do Estado de Sergipe (SEFAZ-SE) que no estado não consta controle e dados precisos sobre a produção, comercialização e transporte da mangaba, por se tratar de produto não tributado pelo Imposto sobre Operações Relativas à Circulação de Mercadorias e sobre Prestações de Serviço de Transporte Interestadual e Intermunicipal e de Comunicação (ICMS). Sendo assim, é fundamental a criação de mecanismos de controle de produção pelo estado para evitar um colapso socioambiental mediante a diminuição drástica dos estoques naturais e cultivados.

Com relação à escala de produção, constatou-se que tanto o fruto oriundo de extrativismo quanto o fruto oriundo de plantio seguem características de uma cadeia produtiva da biodiversidade, na medida que a produção segue o ciclo da natureza, ora com aumento ora com diminuição. Portanto, o preço pago pelo produto não é determinante no aumento ou diminuição da produção, pelo contrário, o aumento ou a diminuição da produção afetam o preço, devido à relação oferta-demanda.

A mesma relação escala de produção-demanda-preço foi encontrada por Calderon (2013) estudando o mercado de PFNM na Amazônia brasileira: o autor afirma que os preços são determinados pelo excesso ou escassez do produto, determinado pela capacidade produtiva das áreas em produção, e pela quantidade demandada. 
Com relação a variações na quantidade do fruto nos últimos anos, há dois perfis entre os atores sociais entrevistados: 1) aqueles que atribuem esta variação à um ciclo natural da espécie e sua relação com o ambiente (tais como inverno/verão e características pluviométricas); e 2) aqueles que afirmam que a quantidade diminuiu, e justificam pela diminuição das áreas nativas de ocorrência da mangaba ou pelo aumento na demanda.

Por sua vez, com relação à variação na qualidade do fruto in natura, os entrevistados afirmaram que se mantém a mesma. Apenas duas referências foram feitas com relação à diminuição da qualidade do fruto, e estavam relacionadas ao fato de que, pela maior demanda, as pessoas retiram o fruto verde, causando perda de qualidade tanto para consumo in natura quanto para consumo de coprodutos, pois o fruto não amadurece corretamente.

Mediante os dados coletados contatou-se que, como em típicas cadeias da biodiversidade, não há qualquer tipo de controle da quantidade e da qualidade dos frutos da mangabeira ofertados no mercado sergipano.

\section{Organização da produção, regulamentação, logística e produto}

Foi constatado que não há contratos entre nenhum tipo de ator social, nem emissão de notas fiscais ou quaisquer outros documentos comprobatórios das transações comerciais. A ausência destes mecanismos é uma característica de cadeias produtivas da biodiversidade que traz preocupação, pois, no caso dos atores sociais extrativistas, afeta diretamente políticas como a Política de Garantia de Preços Mínimos para produtos da Sociobiodiversidade (PGPM-Bio), que necessita de nota fiscal para que seja feito o reembolso do produtor que vendeu o seu produto abaixo do preço de mercado estabelecido pelo governo federal.

A ausência de organização da produção está diretamente ligada à regulamentação das atividades na cadeia produtiva, isto é, reflete na eficiência econômica e distribuição de renda entre os elos da cadeia, visto que não há a observância de quaisquer exigências legais, tais como a assinatura de Carteiras de Trabalho.

Com relação à logística para distribuição do fruto, foi constatado que cada ator social é diretamente responsável pelo escoamento da sua produção, ou por ações próprias ou por intermédio de terceiros, utilizando-se de vias de acesso públicas e meios de transporte tanto públicos quanto privados - isto é, a logística é caótica como é comum em cadeias produtivas da biodiversidade. Na prática, quando não possuem veículos próprios, 
cabe aos atores sociais decidirem entre utilizarem transporte público, utilizarem-se de intermediários e/ou realizarem a contratação de veículos fretados - lembrando que nas duas últimas transações também não há nenhum tipo de documentos comprobatórios.

Esta política de "cada um por si" na comercialização dos frutos parece resultar na estagnação do mercado, que não consegue se expandir pois há dificuldade (gastos elevados em relação ao baixo preço pago pelo fruto) para o fruto in natura chegar aos compradores da região, que dirá sair para estados vizinhos ou até mesmo ultrapassar as fronteiras do país. Ressalta-se que este cenário é encontrado tanto para o fruto in natura quanto para os produtos beneficiados pelas ACM.

Com relação às características do produto para o mercado consumidor, foi relatado pelos detentores do fruto a dificuldade em estocá-los para mantê-los em condições de comercialização, devido aos gastos com a aquisição de freezers e manutenção do funcionamento dos mesmos. Das quatro indústrias participantes da pesquisa, duas relataram dificuldade em obter a mangaba em condições de acondicionamento/higiene adequadas (as demais se responsabilizam pela triagem das mangabas in natura que adquirem), visto que o fruto que chegava às indústrias não atendia às condições mínimas exigidas para a qualidade da polpa e sorvete - assim, passaram aos seus fornecedores a responsabilidade de separar, lavar, ensacar e congelar a mangaba.

É importante destacar que não há controle municipal ou estadual das condições fitossanitárias dos frutos. Este é um aspecto preocupante, pois os frutos que não passam por processo adequado de lavagem e pasteurização podem trazer em si contaminantes, como ocorreu com o açaí na região Norte do país - segundo informações da Fiocruz (2018), desde 2006 havia suspeitas de que o açaí poderia estar contaminado com as fezes do vetor da doença de Chagas e transmitir a doença.

Pelo exposto, nota-se que, nos quesitos organização da produção, logística e características do produto a cadeia produtiva da mangaba encontra-se enquadrada completamente nas características de uma cadeia produtiva da biodiversidade.

\section{Consumidor e marcas}

Nestes aspectos da cadeia produtiva nota-se uma transição entre as típicas cadeias produtivas da biodiversidade e as cadeias produtivas tradicionais. No quesito consumidor, a cadeia produtiva da mangaba se enquadra como uma cadeia produtiva da 
biodiversidade, e, no quesito marcas, parece haver uma transição para uma lógica adotada em cadeias tradicionais.

Com relação à disponibilidade do fruto para o consumidor, foi constatado que é dada em função das variações sazonais que afetam a produção dos pomares nativos e cultivados. Por sua vez, com relação à demanda do fruto pelos consumidores, foi constatado que há baixa demanda da mangaba em face da oferta visto que, tanto atravessadores quanto indústrias informaram que não têm condições de adquirir toda a produção que lhes é oferecida, e, portanto, param de comprar o fruto. Isso gera grande instabilidade na relação fornecedor-consumidor e variação no preço pago pelo quilo do fruto.

Por sua vez, com relação à importância da marca, após a fundação do Movimento das Catadoras de Mangaba (MCM) de Sergipe e a execução do Projeto Catadoras de Mangaba: Gerando Renda e Tecendo Vida em Sergipe, que promoveram o associativismo e o fortalecimento da organização dos atores sociais extrativistas, foi iniciado um processo de valorização dos coprodutos da mangaba, que compõe uma das linhas de produtos comercializada, não só nas sedes das Associações de Catadoras de Mangaba e nas Unidades de Beneficiamento, mas também em uma cooperativa criada no ano de 2014, a Cooperativa de Economia Solidária de Mulheres Extrativistas de Sergipe (COOPMESE).

Desta forma, há controle da qualidade dos produtos, com vistas à obtenção futura de selos de certificações de qualidade e de reconhecimento de origem. Para Calderon (2013) os PFNM e seus coprodutos têm no crescente mercado de produtos orgânicos e naturais opções valiosas para obter vantagem junto ao mercado por meio do desenvolvimento de marcas e o registro de Identificação Geográfica (IG). Segundo Santilli (2005) as IG's associam determinados produtos e serviços a territórios, que são elementos essenciais à reprodução física e cultural das populações tradicionais.

\section{Meio ambiente, espaço de produção e Ciência e Tecnologia (C\&T)}

Em relação à conservação do meio ambiente e ao espaço de produção necessário para produzir o fruto é nítido que a cadeia da produtiva da mangaba traz tanto características de uma cadeia produtiva da biodiversidade quanto de uma cadeia tradicional, visto que, tanto se propaga a ideia de que é possível manter a atividade apenas 
com o extrativismo quanto a de que o enriquecimento de áreas de ocorrência natural da mangabeira é a solução para a espécie que vem sendo constantemente ameaçada.

Foi observado a presença de dois grupos entre os atores sociais entrevistados: no primeiro, encontra-se o discurso do Movimento das Catadoras de Mangaba de Sergipe, com a bandeira do "derruba cerca", isto é, a reinvindicação de acesso livre às áreas onde sempre praticavam o extrativismo da mangaba (SCHMITZ et al., 2011); no segundo grupo, encontram-se os proprietários de terra que almejam pelo enriquecimento de suas áreas onde há ocorrência natural da espécie.

Nesse sentido, a preservação da mangabeira nativa e o plantio comercial são as únicas maneiras de garantir a cultura da mangaba no estado de Sergipe (EMDAGRO, 2009). Em outras palavras, o poder público de Sergipe deve atuar nestas "duas frentes"tanto a conservação e o manejo sustentado em áreas naturais quanto o estímulo ao plantio em propriedades que já possuam mangabeiras por meio do enriquecimento das áreas, a fim de barrar a expansão desordenada do setor imobiliário e da indústria do turismo nas áreas naturais e manejadas com mangabeiras remanescentes.

Em relação à conservação das áreas naturais, é urgente que seja implementada uma política territorial para que o remanescente florestal estadual seja conservado através de estratégias como a criação de Unidades de Conservação (como as de categoria "Reserva Extrativista" - Resex) e concessão do direito de uso de terras paras as comunidades tradicionais de catadoras de mangaba.

A implementação de uma Resex, bandeira levantada pelo Movimento das Catadoras de Mangaba de Sergipe, ainda não foi efetivada. Contudo, ações de concessão de direito de uso de áreas de ocorrência nativa da mangabeira têm ocorrido: em 2018, houve cessão de áreas da União à catadoras de mangaba da região de Indiaroba por meio de um Termo de Autorização de Uso Sustentável (TAUS) (EMBRAPA, 2018; BRASIL, 2018), bem como a doação de terras do munícipio de Barra dos Coqueiros, no litoral norte de Sergipe, à Associação das Catadoras de Mangaba do Município de Barra dos Coqueiros - ACMBC (BARRA DOS COQUEIROS, 2017).

Para a efetiva proteção de áreas de ocorrência de mangabeiras nativas é necessário que haja planejamento e participação coletiva na criação das áreas, a fim de ordenar o acesso e o uso dos recursos, por meio de planos de manejo que se adequem aos diferentes tipos de extrativismo realizados (CALDERON, 2013). Manter a mangabeira em pé é essencial, e, neste sentido, desde o ano de 2015 se discute o Projeto de Lei (PL) 
nº66/2015, de autoria do Deputado João Daniel (PT/SE), que encontra-se até outubro de 2021 com o status "Aguardando Apreciação pelo Senado Federal" de acordo com o site da Câmara dos Deputados ${ }^{5}$ - o referido PL visa proibir o corte e a derrubada da mangabeira em território nacional.

Por sua vez, ressalta-se ainda que para que ocorra a domesticação da espécie e efetivação de plantios comerciais, são necessários estudos que realizem o melhoramento da mangabeira. Neste sentido, Yokomizo (2015) destaca que, como a semente da mangabeira tem um curto período de tempo para germinar e há dificuldades na micropropagação e conservação in vitro, o ideal é que o germoplasma da mangabeira seja conservado em coleções de plantas vivas tanto em áreas cultivadas quanto em áreas nativas.

No estado de Sergipe, a Embrapa Tabuleiros Costeiros (Aracaju, SE) mantém o Banco Ativo de Germoplasma (BAG) da Mangaba - credenciado desde o segundo semestre de 2015 pelo Ministério do Meio Ambiente (MMA) como fiel depositário do patrimônio genético da espécie, reconhecimento oficial que permite maior visibilidade dentro e fora do país e amplia as possibilidades de captação de recursos para manutenção e melhorias (EMBRAPA, 2016).

Neste contexto, com relação à Ciência \& Tecnologia - que engloba também os estudos relacionados ao melhoramento genético - pouco foi posto em prática na cadeia produtiva da mangaba em Sergipe. Conforme aponta Enriquez (2008), em uma cadeia produtiva de características da biodiversidade há a possibilidade de criação de "bioindústrias, mecanismos de capacitação tecnológica e gestão, parques tecnológicos e cooperativas populares" (p. 208).

Fluxograma da cadeia produtiva da mangaba no estado de Sergipe

Diante do exposto, conclui-se que a cadeia produtiva da mangaba possui predominantemente características de uma cadeia produtiva da biodiversidade, com relações diversas entre os atores sociais que lidam diretamente (fluxo de comercialização) e indiretamente (fornecedores de insumos e serviços) com o fruto (Figura 1).

\footnotetext{
${ }^{5}$ Disponível em: https://www.camara.leg.br/proposicoesWeb/fichadetramitacao?idProposicao=1198926
} 
Figura 1 - Complexo Agroextrativista da Mangaba em Sergipe. (Legenda: setas verdes - processo de coleta; setas azuis - processo de venda/compra no sentido da seta; retângulos azuis - fonte do recurso em questão (mangaba); retângulos laranjas - atores do fluxo de comercialização; retângulos amarelos - coprodutos oriundos da mangaba in natura; espaço tracejado - relações estabelecidas no fluxo de comercialização; espaço não tracejado - atores provedores de insumos e serviços).

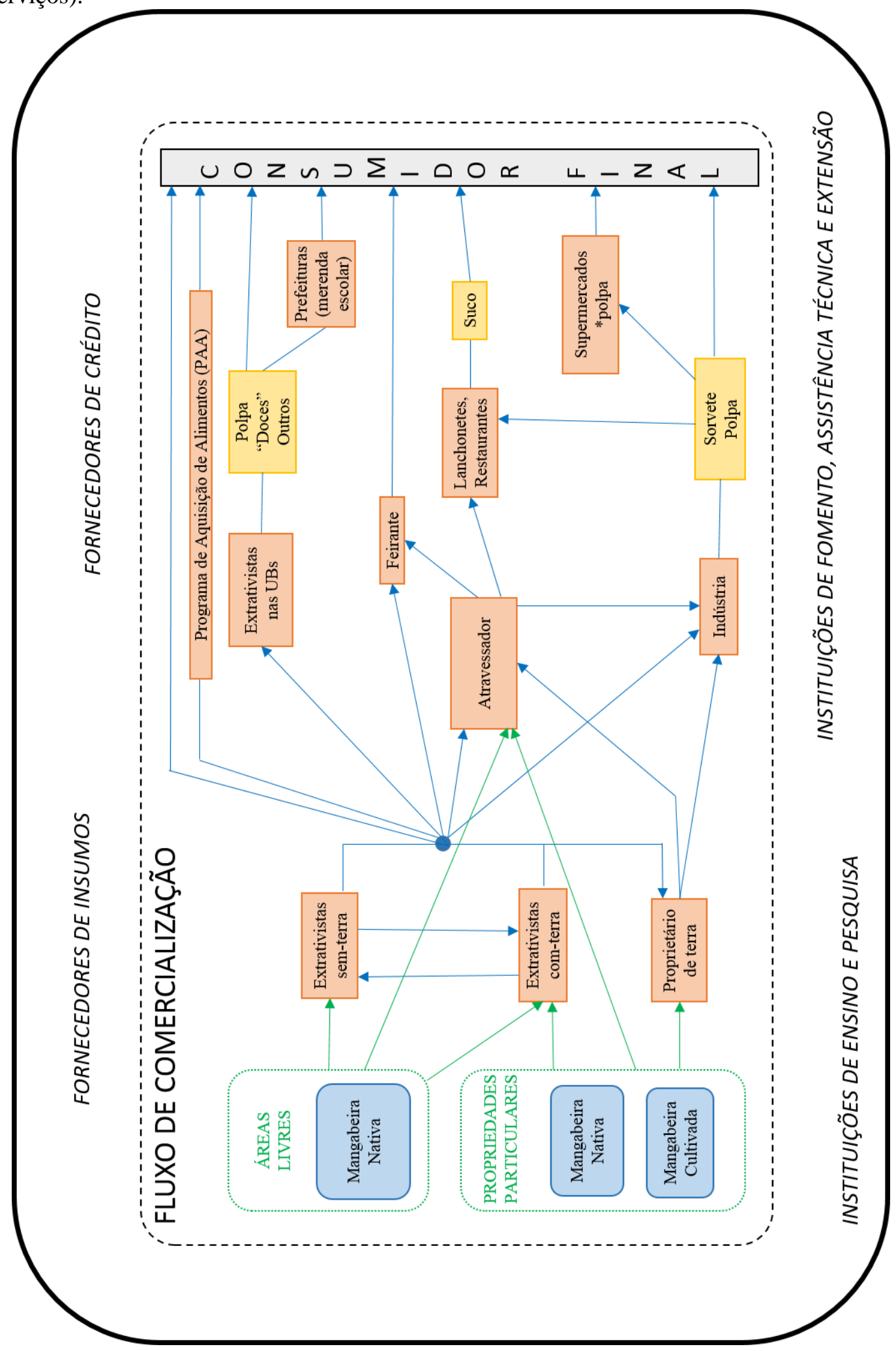

Fonte: Pesquisa, 2018. 
Foi possível identificar que os dois modelos (cadeia produtiva tradicional e cadeia produtiva da biodiversidade) são representados a partir de uma mesma matéria prima - o fruto da mangabeira - e que, embora os dois modelos operem em um mesmo ambiente, constituem dinâmicas de produção e de comercialização diferentes. A produção é proveniente de plantas nativas em áreas livres, plantas nativas em áreas privadas e plantas cultivadas em áreas privadas; por sua vez, a comercialização é feita, no primeiro momento, pelo extrativista individualmente, pelo extrativista associado e pelo proprietário de terra (depois seguindo para os intermediários e indústrias).

Neste sentido, entende-se que a cadeia produtiva da mangaba no estado de Sergipe se configura como um Complexo Agroextrativista da Mangaba (CAEM) em que há três subestruturas de cadeia produtiva, que se inter-relacionam após a base da cadeia, porém, possuem dinâmicas de produção e comercialização distintas: extrativismo tradicional, extrativismo associativista e produção comercial (plantio). Na subestrutura "extrativismo tradicional" há os catadores de mangaba não associados às ACMs e que realizam tradicionalmente a coleta e venda dos frutos; na subestrutura "extrativismo associativista" há os catadores de mangaba associados às ACMs e que realizam, além do extrativismo tradicional, a fabricação e venda de coprodutos; por sua vez, na subestrutura produção comercial (plantio) encontram-se os proprietários de terra que investiram no plantio de mangabeiras em suas áreas.

\section{CONCLUSÃO}

Constatou-se que a cadeia produtiva da mangaba no estado de Sergipe segue, de modo predominante, a lógica de uma cadeia produtiva "da biodiversidade", apesar de haverem iniciativas no sentido de implementar o plantio comercial da espécie e de agregar valor aos produtos por meio da atribuição de marca - características comuns à uma cadeia produtiva tradicional.

Isto é, configura-se como uma cadeia dinâmica, com particularidades complexas que precisam ser melhor compreendidas para, além de defini-la, buscar alternativas que promovam o uso sustentável da mangabeira e dos demais recursos naturais a ela associados, permitindo, concomitantemente, o alcance da sustentabilidade socioeconômica de todos os atores sociais e a sustentabilidade ambiental no uso dos ecossistemas envolvidos. 
É necessário compreender que o caráter dinâmico encontrado na cadeia produtiva da mangaba no estado de Sergipe confere a ela um status diferenciado, no qual os modelos de estudo "tradicionais" e os "da biodiversidade" nem sempre são representativos. Neste sentido, a pesquisa identificou um Complexo Agroextrativista da Mangaba (CAEM) no estado de Sergipe, composto por três estruturas de cadeia produtiva com dinâmicas de produção e comercialização distintas: extrativismo tradicional, extrativismo associativista e produção comercial (plantio).

Cada um dos três ramos do CAEM no estado de Sergipe tem características e demandas próprias e, destaca-se, se relacionam entre si, sendo necessários diferentes caminhos para o fortalecimento das lógicas adotadas em cada uma das cadeias. Portanto, é necessário que o poder público seja estimulador e mediador no diálogo entre os atores sociais envolvidos a fim de conciliar os conflitos e alcançar um denominador que permita o alcance da gestão coletiva dos recursos de base extrativa.

$\mathrm{Na}$ atual conjuntura, verifica-se que no estado de Sergipe o uso da biodiversidade regional é ignorada. A mangaba, por exemplo, apesar de ser reconhecida na lei como símbolo do estado, tem as atividades de extrativismo, plantio e comercialização realizadas sem nenhum tipo de acompanhamento (ou controle) do Poder Público estadual e municipais. Além da falta de acompanhamento das atividades do fluxo de comercialização, não há Planos de Manejo das áreas de ocorrência natural de mangabeiras, contribuindo para a exploração desordenada do fruto.

A mangaba tem o potencial de contribuir para o desenvolvimento regional sustentável, desde que seu uso seja institucionalizado por meio de políticas públicas estaduais que conservem a mangabeira, estimulem o plantio para enriquecimento de áreas de ocorrência natural da espécie, protejam as comunidades e povos tradicionais e a cultura do extrativismo da mangaba, promovam a distribuição justa de renda entre os diferentes elos do fluxo de comercialização, dentre outras.

Ressalta-se que o estímulo ao diálogo e à participação dos interessados é o único meio de traçar alternativas viáveis que contemplem todos os interessados na exploração do fruto - e, entende-se, que este estímulo deve vir prioritamente do poder público estadual. Na conjuntura atual, a falta de diálogo entre os diferentes atores sociais envolvidos e a carência de políticas públicas que norteiem a coleta do fruto são entraves ao alcance da sustentabilidade da cadeia produtiva da mangaba no estado de Sergipe. 


\section{REFERÊNCIAS}

ALBUQUERQUE, U. P. de; LUCENA, R. F. P. de; NETO, E. M. de F. L. In Albuquerque, U. P. (Org.) (Editors). Methods and Techniques in Ethnobiology and Ethnoecology. New York: Humana Press. v. 1, 2014. p. 1-14.

ARAÚJO, M. J. Fundamentos de agronegócios. 2 ed. 4. Reimpr. São Paulo: Atlas, 2009.

BARRA DOS COQUEIROS. Câmara Municipal de Barra dos Coqueiros. Lei no 859 de 18 de abril de 2017. Dispõe sobre a doação do terreno, do Patrimônio Municipal à Associação de Catadoras e Catadores de Mangaba do Município de Barra dos Coqueiros e dá outras providências. Disponível em:

https://cmbarradoscoqueiros.se.gov.br/sites/cmbarradoscoqueiros.se.gov.br/files/legislac ao_e_atos/LEI\%20N\%C2\%BA\%20859.2017\%20-

$\%$ 20DISP\%C3\%95E\%20SOBRE\%20A\%20DOA\%C3\%87\%C3\%83O\%20DE\%20TER RENO $\% 20$ A $\% 20$ ASSOCIA $\%$ C3\%87\%C3\%83O\%20DAS\%20CATADORAS\%20E\%2 0CATADORES\%20DE\%20MANGABA.pdf Acessado em: 20.10.2021

BATALHA, M. O. (Coord.). Gestão Agroindustrial: GEPAI: Grupo de estudos e pesquisas agroindustriais. 3 ed. São Paulo: Atlas, 2007.

BRASIL. Diário Oficial da União. N 2, quarta-feira, 3 de janeiro de 2018. Seção 3. Página 100. Disponível em:

http://www.mma.gov.br/images/_noticias_fotos/2018/taus.pdf Acessado em: 27.04.2018.

BRASIL. PAA - Programa de Aquisição de Alimentos (folder). Brasília: Ministério do Desenvolvimento Agrário. Secretaria da Agricultura Familiar, 2012. Disponível em: http://www.mda.gov.br/sitemda/sites/sitemda/files/user_arquivos_64/folder_paa_2012.p df Acessado em: 21.04.2018.

CALDERON, R. de A. Mercado de produtos florestais não madeireiros na Amazônia brasileira (Tese de Doutorado). Universidade de Brasília, Faculdade de Tecnologia, Departamento de Engenharia Florestal: Brasília, 2013.

EMBRAPA. Empresa Brasileira de Pesquisa Agropecuária. Banco genético de mangaba da Embrapa em Sergipe recebe credenciamento oficial. Notícia vinculada no portal em 20.01.2016. Disponível em: https://www.embrapa.br/busca-de-noticias//noticia/9130064/banco-genetico-de-mangaba-da-embrapa-em-sergipe-recebecredenciamento-oficial Acessado em: 07.05.2018

EMBRAPA. Embrapa Tabuleiros Costeiros. Notícia no Portal. Termo assegura direitos para catadoras de mangaba e pescadores. Notícia vinculada no portal em 18.01.2018.Disponível em: https://www.embrapa.br/tabuleiros-costeiros/busca-denoticias/-/noticia/31409408/termo-assegura-direitos-para-catadoras-de-mangaba-epescadores Acessado em: 22.04.2018.

EMDAGRO. Empresa de Desenvolvimento Agropecuário de Sergipe. Notícia no portal, 2009. Cultivo comercial da mangaba pode mudar vida de produtores. Disponível em: http://www.emdagro.se.gov.br/modules/news/article.php?storyid=150 Acessado em: 19.08.2015 
ENRIQUEZ, G. E. V. Desafios da sustentabilidade na Amazônia: biodiversidade, cadeias produtivas e comunidades extrativistas integradas (Tese de Doutorado). Universidade de Brasília: Brasília, 2008.

FIOCRUZ. Fundação Oswaldo Cruz. Açaí contaminado com parasito pode transmitir doença de Chagas. Disponível em:

http://www.fiocruz.br/portalchagas/cgi/cgilua.exe/sys/start.htm?infoid=2\&sid=1

Acessado em: 07.05.2018.

GOMES, L. J. Extrativismo e Comercialização da Fava-D'anta (Dimorphandra spp): Um Estudo de Caso na Região de Cerrado de Minas Gerais. (Dissertação de Mestrado). Universidade Federal de Lavras - UFLA, 1998.

IBGE. Instituto Brasileiro de Geografia e Estatística. Produção da Extração Vegetal e Silvicultura 2005. v.20. Rio de Janeiro. Disponível em:

https://biblioteca.ibge.gov.br/visualizacao/periodicos/74/pevs_2005_v20.pdf Acessado em: 26.04.2018

IBGE. Instituto Brasileiro de Geografia e Estatística. Produção da Extração Vegetal e Silvicultura 2007. v.22. Rio de Janeiro. Disponível em:

https://ww2.ibge.gov.br/home/estatistica/economia/pevs/2007/default.shtm Acessado em: 29.12.17

IBGE. Instituto Brasileiro de Geografia e Estatística. Produção da Extração Vegetal e Silvicultura 2016. v.31. Rio de Janeiro. Disponível em:

https://biblioteca.ibge.gov.br/visualizacao/periodicos/74/pevs_2016_v31.pdf Acessado em: 29.12.17

IEF-MG. Instituto Estadual de Florestas de Minas Gerais. Plano Estadual de Fomento Florestal, 2012. Disponível em:

http://www.ief.mg.gov.br/images/stories/Florestas/plano\%20estadual\%20de\%20foment o\%20-\%20verso\%20final\%201.pdf Acessado em: 06.05.2018.

JESUS, N. B. de. Relações socioambientais no extrativismo da aroeira (Schinus terebenthifolius Raddi) no baixo São Francisco SE/AL. (Dissertação de Mestrado): São Cristóvão. Universidade Federal de Sergipe, 2010.

JESUS, N. B. de; GOMES, L. J. Configuração Social e Identidade no extrativismo da aroeira (Schinus terebinthifolius Raddi) no Baixo São Francisco Sergipe/Alagoas. In SANTOS, A. C. dos et al. (Orgs). Pensar a (in) sustentabilidade: desafios à pesquisa. Porto Alegre, RS: Redes Editora, 2010. p.181 a 196.

LAKATOS, E. M. Metodologia científica. 5ª ed. São Paulo: Atlas, 2008.

LÊDO, A. da S. (Org.). A cultura da mangaba. Brasília. DF: Embrapa, 2015.

Disponível em:

https://ainfo.cnptia.embrapa.br/digital/bitstream/item/165360/1/PLANTAR-

MANGABA-ed01-2015-MIOLO.pdf Acessado em: 25.06.2018.

MARCONI, M. de A; LAKATOS, E. M. Técnicas de pesquisa: planejamento e execução de pesquisas, amostragens e técnicas de pesquisa, elaboração, análise e interpretação de dados. 7. ed. São Paulo: Atlas, 2008. 
MAROTTI, J. et al. Amostragem em pesquisa clínica: tamanho da amostra. Revista de Odontologia da Universidade Cidade de São Paulo 20(2): 2008, p.186-194.

MOTA, D. M. da. et al. A mangabeira as catadoras o extrativismo. Belém, PA: Embrapa Amazônia Oriental; Aracaju: Embrapa Tabuleiros Costeiros, 2011a.

MOTA, D. M. da. et al. As senhoras da mangaba. In A mangabeira as catadoras o extrativismo. Belém, PA: Embrapa Amazônia Oriental; Aracaju: Embrapa Tabuleiros Costeiros, 2011b. p.105-137

OLIVEIRA, D. M. de. et al. Identificação dos pontos críticos no sistema extrativista da mangaba (Hancornia speciosa Gomes) em Sergipe. Guaju, Matinhos, v.3, n.1, 2017, p. 11-36.

PEREIRA, E. B. C.; PEREIRA, A. V; JUNQUEIRA, N. T. V. Propagação por sementes. In SILVA JÚNIOR, J. F. da; LÉDO, A. da S. (editores) A cultura da mangaba. Aracaju, SE: Embrapa Tabuleiros Costeiros, 2006. p.92 a 109

PEREIRA, E. O. et al. Mapa do extrativismo da mangaba em Sergipe: ameaças e demandas. Aracaju: Embrapa Tabuleiros Costeiros. Aracaju: Embrapa Tabuleiros Costeiros, 2009.

PEREIRA, E. O. et al. Mapa do extrativismo da mangaba em Sergipe: ameaças e demandas. Dados vetoriais do geoprocessamento. Aracaju: Embrapa Tabuleiros Costeiros, 2010.

RODRIGUES, R. F. de. A. et al. (Org.) Mapa do extrativismo da mangaba em Sergipe: situação atual e perspectivas. Brasília, DF: Embrapa, 2017.

SANTILLI, J. As Indicações Geográficas e Territorialidades Específicas das Populações Tradicionais, Povos Indígenas e Quilombolas. In LAGES, V.; LAGARES, L.; BRAGA, C. L. (Orgs) Valorização de produtos com diferencial de qualidade e identidade: indicações geográficas e certificações para competitividade nos negócios. Brasília: Sebrae, 2005. p. 203-217.

SCHMITZ, H. et al. Conflitos e movimento social: ameaças e reações das catadoras de mangaba. In MOTA, D. M. da. et al. A mangabeira as catadoras o extrativismo. Belém, PA: Embrapa Amazônia Oriental; Aracaju: Embrapa Tabuleiros Costeiros, 2011. p.251-290.

SCHMITZ, H.; MOTA, D. M. da; SOUZA, G. M. O Fim do Programa de Aquisição de Alimentos: reviravoltas para mulheres extrativistas em Sergipe. Política \& Sociedade Florianópolis - Vol. 15 - Edição Especial, p.80-103, 2016.

SERGIPE. Decreto n. ${ }^{\circ} 12.723$ de 20 de janeiro de 1992. Institui a Mangabeira, como Árvore Símbolo do Estado de Sergipe, e dá providências correlatas. Disponível em: http: https://www.adema.se.gov.br/wp-content/uploads/2017/03/decreto_n_12.72392.pdf Acessado em 20/10/2021.

SERGIPE. Lei $\mathrm{n}^{\circ} 7.082$ de 16 de dezembro de 2010. Reconhece as catadoras de mangaba como grupo cultural diferenciado e estabelece o auto-reconhecimento como critério do direito e dá outras providências. Disponível em: 
http://www.catadorasdemangaba.com.br/includes/cdmangaba/13/Lei288-2010.pdf

Acessado em 11/09/2015

SERGIPE. Secretaria de Estado do Meio Ambiente e dos Recursos Hídricos de Sergipe. Florestas em Sergipe: Construindo uma Política Florestal, 2012. Disponível em: http://docs.wixstatic.com/ugd/609f7a_8b2cf3ee98351008e265554b6f1c305b.pdf Acessado em: 06.05.2018.

SILVA JUNIOR, J. F. da. et al. "Rainha dos Tabuleiros": a mangabeira em Sergipe. In MOTA, D. M. da. et al. A mangabeira as catadoras o extrativismo. Belém, PA: Embrapa Amazônia Oriental; Aracaju: Embrapa Tabuleiros Costeiros, 2011. p.79-101.

SILVA JÚNIOR, J. F. da; LÉDO, A. da S. (editores). A cultura da mangaba. Aracaju, SE: Embrapa Tabuleiros Costeiros, 2006.

SILVA JUNIOR, J. F. da; MOTA, D. M. da; SCHMITZ, H. No rastro da mangabeira. In MOTA, D. M. da. et al. A mangabeira as catadoras o extrativismo. Belém, PA: Embrapa Amazônia Oriental; Aracaju: Embrapa Tabuleiros Costeiros, 2011. p.45-76

SILVA, R. R. V. da; GOMES, L. J; ALBUQUERQUE, U. P. Methods and Techniques for Research on the Supply Chains of Biodiversity Products. In: ALBUQUERQUE, U. P. (Org.) (Editors) Methods and Techniques in Ethnobiology and Ethnoecology. New York: Humana Press, v. 1, 2014. p. 335-348

VERDEJO, M. E. Diagnostico Rural Participativo - DRP: Um guia prático. Secretaria da Agricultura Familiar - Ministério do Desenvolvimento Agrário - MD, Brasília, 2006.

YOKOMIZO, G. K. A mangabeira e os principais aspectos do seu melhoramento genético na Embrapa Amapá. Macapá: Embrapa Amapá, 2015. 